\section{Brussels' subsidy to shift away from infrastructure}

[MUNICH] European Commission proposals aimed at encouraging poor countries and regions to spend more of their European Union (EU) subsidies on research, but placing less emphasis on building new facilities, will be considered in Brussels this week.

If accepted, the recommendations which are in line with broader EU policy reforms on 'economic and social cohesion' due to be introduced after 2000 - will be presented to the European Parliament and Council of Ministers for discussion.

The subsidies, known as 'structural funds', will continue after 2000 with the aim of promoting competitive development in poor regions (see Nature 385, 192-193; 1997). But regions and countries eligible for the funds will be encouraged to spend a higher proportion on research than they do now. They will also be encouraged to spend more of the funds allocated for research on training, innovation, technology transfer and dissemination of results.

The building of infrastructure facilities has previously been generously funded. Structural fund spending on research has increased to 5.7 per cent of the total from 3.9 per cent in the early 1990 s, but the technology gap between poor and rich countries and regions has closed only slightly.

The new round of structural funds, covering the period 2000-2006, will total ECU275 billion (US\$297 billion), including ECU45 billion earmarked for new EU members. The proportion dedicated to research is likely to be comparable to the budget of the commission's fifth Framework programme for research, which will be about ECU16 billion (see below). And the new philosophy on structural funds complements that on the latest Framework programme, which renews emphasis on the dissemination and exploitation of results.

Alison Abbott

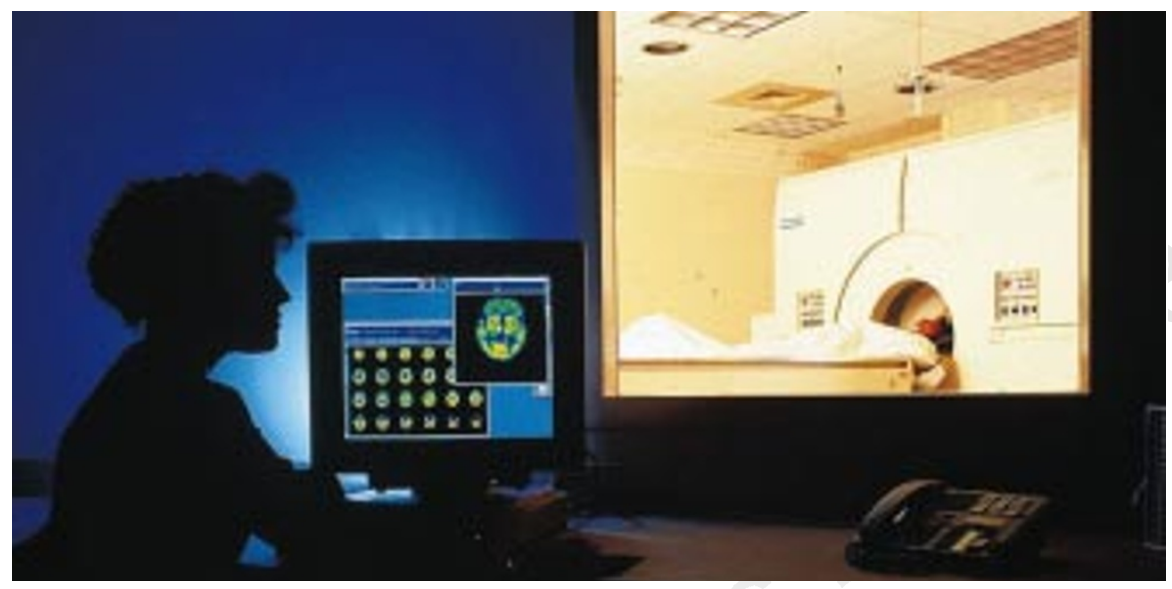

Brain invaders: could cerebral imaging techniques such as PET scanning pose a risk to privacy?

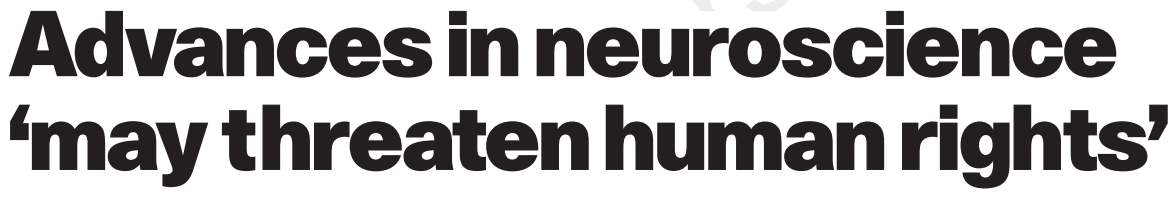

[PARIS] Neuroscience is being increasingly recognized as posing a potential threat to human rights, just as another area of biology - research in human genomics - may lead to an excessive focus on genetic determinism and raises the spectre of genetic discrimination. This was one of the conclusions to emerge from the annual public meeting of the French national bioethics committee held last week in Paris on the theme of 'Science and Racism'.

Jean-Pierre Changeux, the chairman of the committee and a neuroscientist at the Institut Pasteur in Paris, told the meeting that understanding the working of the human brain is likely to become one of the most ambitious and rich disciplines of the future.

But neuroscience also poses potential risks, he said, arguing that advances in cerebral imaging make the scope for invasion of privacy immense. Although the equipment needed is still highly specialized, it will become commonplace and capable of being used at a distance, he predicted. That will open the way for abuses such as invasion of personal liberty, control of behaviour and brainwashing. These are far from being science-fiction concerns, said Changeux, and constitute "a serious risk to society".

Denis Le Bihan, a researcher at the French Atomic Energy Commission, told the meeting that the use of imaging techniques has reached the stage where "we can almost read people's thoughts".

The national bioethics committee is taking such threats so seriously that it is launching a study to consider the issues and recommend possible precautions. The study will also cover more immediate issues such as the legal question of whether criminals are responsible for their actions; Changeux predicts an increase in defence arguments based on irresponsibility due to a genetic predisposition to certain types of behaviour.

In closing the meeting, Claude Allègre, the minister for national education, research and technology, hinted at the creation of a revamped parliamentary office of technology assessment, arguing that the national bioethics committee's approach in the life sciences needed to be applied to other areas of science.

DeclanButler

\title{
Framework themes grow to four, but budget stays the same
}

[MUNICH] The European Commission has increased the number of themes in its next five-year Framework programme for research from three to four, but is retaining the original budget figure.

The addition of a theme to the programme, which is due to start next year, is a response to proposals from the European Parliament (Nature 391, 3; 1998).

The parliament had also proposed a small increase in the budget of the fifth Framework programme (FP5). But the final proposal, released in Brussels last week and to be presented shortly to member states as represented by the Council of Ministers, sticks to the original budget of ECU16.3 billion (US\$17.6 billion.)

In addition, the parliament had suggested making terminology more straightforward, but the commission rejected this and will keep its less-precise naming tradition.

Thus the names suggested for the four thematic programmes are: 'improving the quality of life and the management of living resources'; 'creating a user-friendly information society'; 'promoting competitive and sustainable growth'; and 'preserving the ecosystem'. The commission does not want to separate energy and environment in the last-named programme. although the parliament had asked that each of these have its own budget line.

The commission also added two more targeted programmes-within-programmes — 'key actions' — to a list it had hoped to limit to 16. The additions are 'the ageing population' and 'global environmental change and climate'.

The commission's revised proposals are due to be discussed by the research ministers of the 15 member states, meeting as the Council of Europe, in mid-February. 